\title{
Academic writing for publication: putting the 'international' into context
}

\section{Introduction}

Research has revealed the increasing impact of higher education evaluation regimes on academics' decision making about where and how to publish their work. In particular, publishing in English in journals based in the Global North has been identified as of central concern to individual academics for job promotions and for institutions aiming to climb up university league tables. There is also growing evidence that higher education institutions (HEIs) in the Global South are adopting similar indicators of academic quality. However, there has been limited research into how scholars in these contexts view and participate in academic journal publishing, including mediating their research and writing for an international audience.

Canagarajah's (2002) seminal ethnographic research analysed the publishing experiences of academics in a Sri Lankan university, including their engagement as readers and writers with what he terms 'centre-based'1 journals. His distinction between practical barriers to publication (such as lack of resources for conference attendance or limited internet access) and the 'discursive' constraints (unfamiliarity with the rhetorical conventions of UK/US-based journals) faced by such academics has led to practical interventions to address these inequalities (see Lillis, Magyar and Robinson-Pant 2010). Whilst mentoring programmes have gone some way to enabling scholars from the Global South to publish in centre-based

\footnotetext{
${ }^{1}$ As Canagarajah notes (2002:7), these concepts from dependency theory focus attention on the 'intellectual and material inequalities between the center (referred to... as the West) and periphery (typically communities colonised by European intervention)'. Though sociolinguists (like Canagarajah) writing in this area tend to prefer the terms 'centre/periphery', we have chosen to use 'Global North/South' (commonly used in development studies) to discuss unequal global relationships. As Dados and Connell (2012: 12) point out, 'The use of the phrase Global South marks a shift from a central focus on development or cultural difference toward an emphasis on geopolitical relations of power'.
} 
journals, this could be seen as a 'deficit' approach, in that the problem has been located within the individual scholar, rather than the global institutions involved. In particular, the hierarchical relationships identified nearly two decades ago by Canagarajah in relation to the geopolitics of academic publishing have remained largely unchallenged.

As educational researchers based in Oman, Ethiopia and the UK, we came together in Cairo at a symposium organised by Compare, a UK-based journal, in 2017 to explore ways of addressing these institutional inequalities around academic publishing. This included enhancing the access of individual writers to higher status publishing (through workshops and a mentoring programme). But, more significantly, senior academics were invited to share ideas on how to challenge and transform the values and practices of centre-based journals including assumptions about writing, peer reviewing and editing, which are often unquestioned by editors, writers and reviewers. This symposium involved analysing regional, national and institutional journals published in participants' countries and resulted in a wideranging discussion of reviewing practices, language issues, research priorities and resources. Since this event, we have continued to reflect on these questions - which are broadly around 'whose knowledge (and ways of disseminating research) counts' - through research conducted with academics in diverse contexts in the Global South.

In this article, we set out to explore how academics in Ethiopia and Oman engage with decisions around academic writing and publishing. There has been much research into influences on knowledge production in relation to international journals, particularly from the starting point that such high stakes publishing is desirable and looking at academics' experiences of interacting with such institutions. We consider that this is only part of the context which needs to be considered in relation to academic publishing and knowledge 
construction. For this reason, we are taking a broader lens on academics' writing practices in the two case study universities to ask how do these different higher education contexts shape people's experience of publishing? This encouraged us to problematise the meaning of 'international' in these two contrasting contexts, as well as to investigate how specific university priorities influence knowledge production and dissemination. We hope that this exploration will also help to avoid the tendency to polarise and homogenise writing practices in both the Global South and North.

\section{The geopolitics of academic publishing: what are the issues?}

There is a growing body of research on the impact of English-medium publication on knowledge construction. As Curry and Lillis (2017) note, there is great pressure for scholars to publish in English in high status journals, with negative consequences for those who do not do so, 'such as being passed over for promotion, being denied salary increases... or to receive research funding' (ibid: 1). On a macro level, they suggest that codified 'evaluation regimes' using metrics of academic output, 'instantiate the larger context of the "knowledge economy", providing the frame for viewing academic publications as a measurable commodity, one that affects not only individual scholars' careers but also the broader ability of a nation state or region to generate knowledge...' (ibid: 3).

This imperative for all researchers to aim for 'high stakes' publishing has enormous implications for academic publishing and knowledge construction, particularly in countries of the Global South. As Canagarajah pointed out in 2002, a local researcher in Sri Lanka would have to turn to research published in a 'centre' journal by a researcher from the Global North to find out about schools in Sri Lanka: 'Due to the one-sided nature of publishing, we are forced into a position of understanding ourselves through center eyes' (Canagarajah, 2002: 
237). This leads to inequalities in knowledge production and circulation as knowledge produced in the Global North is often seen as superior to that produced in the Global South (Windle, 2020). Further, at an institutional level, Salager-Meyer (2015: 22) argues that this focus on 'research that appeals to an international audience' and the consequent 'publication drain' has led to the demise of what she terms 'peripheral/ "small" journals'. These may be journals published in the national or local language, produced for smaller readerships and focusing on national policy or context-specific debates. She refers to the difficulty of sustaining 'small journals', in relation to Lee and Lee's (2013:226) account of domestic Korean journals, described as the 'graveyard' for papers rejected by international (English-written) journals (Salager-Meyer, 2015: 24). As Curry and Lillis (2017) suggest, the challenges faced by individual scholars and by national/local journals raise the question of "how multilingual scholars can participate more equally in global academic knowledge production' (ibid: 9)

Aside from equity issues, there is increasing concern about the dominance of writing conventions taken from centre-based journals, to the extent that these are usually taken as the unquestioned norm, leading to a lack of diversity in form and style. Such practices are not confined to centre-based journals as they become recognised by periphery-based journals as a marker of quality. As Adamson and Muller (2017) found from their research with an Asian regional journal, 'review staff investigated appear to hold to Anglophone-centric standards... expecting authors to address an idealized audience in their writing, rather than allowing authors to present their local contexts as legitimate in their own right' ( $p$ 531). This is not just about the content or topics covered, but also relates to the assumption of such journals that authors should write for an 'international' audience 'in a language they see as distant from 
their ways of thinking and that excludes access to the local community affected by the research results' (Arnsbjornsdottir and Ingvarsdottir, 2015).

The question of context - including deciding when and how to reference knowledge - is a particular challenge for scholars in the Global South when writing for centre journals. Peer reviewers often require the author to provide more contextual information if they are unfamiliar with the country or to require more explanation and references to support what appears to the author to be 'common knowledge'. Robinson-Pant and Wolf (2017: 105) offer a broader conceptualisation of 'context' as 'being not simply the background knowledge required to interpret fieldwork data, but also an anticipation of the linguistic and cultural resources that a reader might bring to the text'. Ironically, a writer in the UK may not need to be as responsive to multiple audiences as a writer in Ethiopia, even if writing for an international journal - since the journal peer reviewers are more likely to come from or be familiar with countries in the Global North.

The definition of an international journal has tended to be seen in terms of 'Anglophone country' gatekeepers, though the connection between journal and language hierarchies can be contended. Many researchers in the Global South (as in Ethiopia), having been educated in English-medium schools and universities due to colonial legacies, prefer to write and publish in the English language. Yet journals published in such countries are still not positioned as 'international'. The frequent conflation of 'international' with 'quality' in HE regimes of evaluation has been highlighted by Bridges (2017) and whether or not a journal is regarded as 'international' is of great significance in relation to broader inequalities and institutionalised hierarchies in global knowledge production, influencing 'who is picked up, cited and positioned as important' (Fejes, 2016:1). For this reason, we are particularly 
interested to problematise 'international' in relation to journals and consider how respondents in the case study universities in Ethiopia and Oman interpreted this term.

Though much of the literature on the geopolitics of academic writing has focused on the 'centre' versus 'periphery' dichotomy, Kuteeva and Mauranen (2014: 1) observe that 'many changes have taken place both in international publishing and associated linguistic practices'. Their nuanced account (ibid: 3 ) of the growing influence of multilingual scholars rejects earlier assumptions that 'non-native speaking informants... necessarily feel disadvantaged or "stigmatized" (Flowerdew 2008) by default'. Drawing on the above debates around meanings of 'international', hierarchies of knowledge and the dominance of 'centre' journal practices, we set out to investigate and compare the institutional practices, values and identities that influence academics' writing and publishing decisions in two universities in Ethiopia and Oman.

\section{Knowledge production in Oman and Ethiopia: understanding the context}

Our decision to select universities in such contrasting countries was partly pragmatic (as two of the authors come from Ethiopia and Oman). However, we also believe that the comparative analysis can reveal insights into how the broader country and regional contexts - including publishing infrastructure and regulation, language hierarchies and higher education policies - shape academics' decisions about publishing and writing.

Over the past decades, there have been growing concerns about knowledge production in the Arab world. Research studies indicate that Arab scholars' contribution to global scientific knowledge is quite low when compared with the overall international research output (Abouchedid \& Abdelnour, 2015). While there is some evidence suggesting that the situation has improved, variations have been noted in terms of knowledge production patterns across 
different disciplines, with international publications in science and technology significantly outnumbering those in the social sciences and humanities sector (Ibrahim, 2018). This is not surprising given that, unlike social sciences and humanities-related subjects which are taught through the medium of Arabic, science and technology subjects are usually taught in English. The limited Arab contribution to the international literature in social sciences has been documented in several research reviews (see El-Zeki, 2008; Hallinger \& Hammad, 2019). For example, a review of educational research papers published in international journals between 1995 and 2006 found that only 36 articles were related to the Arab region, representing only $1.7 \%$ of the total number of papers (2112) published (El-Zeki, 2008). While we acknowledge the limitation of using international publication counts as the only measure of contribution to international knowledge, the low productivity of Arab countries in terms of wider indicators of scientific knowledge is well documented (see Abouchedid \& Abdelnour, 2015; Almansour, 2016; Hanafi \& Arvanitis, 2015). Hanafi \& Arvanitis (2015) observe that several political, institutional, cultural, and financial barriers have long hampered these countries' efforts to transform into 'knowledge societies'.

This evidence of Arab researchers' limited contribution to global knowledge production may also be attributed to a lack of access to scholarly international journals due to language barriers. This is despite the spread of English as a medium of instruction in many Arab HEls (Findlow, 2006), which has been accompanied by an increasing trend of marginalising the Arabic language in favour of English for social science research publication. Globalisation, internationalisation and commodification of higher education have contributed to the development of HEls, especially in the Arabian Gulf states, with promotion systems favouring publication in high impact international journals (Hanafi \& Arvanitis, 2014). These policies have given rise to what Hanafi (2011) describes as 'compartmentalised elites' among Arab 
scholars: 'either elite that publish globally and perish locally or elite that publish locally and perish globally' (Hanafi, 2011: 291).

The above-mentioned trend has been particularly notable in the Arabian Gulf countries, including Oman, which have undergone significant economic, social, political and cultural developments over the past few decades. As part of their nation building strategies, these countries invested massively in establishing HEls, many of which, especially in the private sector, offer Western-style education characterised by the use of English as the language of instruction (Findlow, 2006). They have also responded to the pressures of globalisation and World University Rankings by adopting policies forcing faculty members to publish in international journals (Hallinger \& Hammad, 2019). However, it is also important to note that all major universities in the Gulf, including the Omani university where this research was conducted, have their own (in-house) journals which cover a wide range of disciplines spanning the sciences and humanities. While science journals publish in the English language, humanities journals mainly publish Arabic-language research, but may also accept papers written in English. The vast majority of Arabic journals in the Gulf are not open-access, so they do not charge publication fees.

Turning to the East Africa region, English has long been a medium of instruction in schools and Higher Education so the majority of academics in all disciplines publish in English, even in national/local journals. Mohamedbhai (2013) noted that Africa produces only $1.1 \%$ of the world's publications and only few papers are published in internationally recognised journals. In Ethiopia, the publication of scholarly journals started in the 1960s (ESA, 2017). From then on, the number of journals increased steadily from six in the 1960s to 72 in 2017 (ibid). Following the expansion of higher education in the country in the last two decades, the 
demand to find outlets for publications has increased (Lulseged \& Howe, 2020). As a result, many HEls established their own journals for academic publishing. Out of the 72 scholarly journals in $2017,65 \%$ were established in the last fifteen years and most are owned by public HEIs (45) and national professional societies (19) (EAS, 2017).

However, some studies on Ethiopian journals revealed concerns about quality and relevance, particularly around the delay of reviewer responses, superficial review reports, low scholarly writing skills of staff, publishing a diversity of unrelated subjects, limited online visibility, and inexperienced editors (ibid). These issues added to a lack of motivation to publish, insufficient research funding, inadequate methodological and technical skills to produce publishable work, too little research time due to teaching assignments, and absence of a conducive research environment have led to a low output of research outcomes among faculty (Derebssa, 2004). Even in published articles, concerns around content and methodological issues have been observed (Tesfaye, 2011). To improve the quality of local journals, the Ethiopian Science Academy (ESA, 2017) and the Ministry of Science and Higher Education (MOSHE, 2019) recently introduced a national system of journal evaluation and accreditation. Previously, the practice with regard to determining the reputability of journals was the mandate of university senates.

Another issue of concern among faculty is the increasing tendency to publish in what are labelled as 'predatory journals' which bypass the customary peer-review process, ask for publication and article processing fees, and publish any paper 'with questionable scientific value' (Cook, 2007, p. 1). In a study by Demir (2018), faculty at Ethiopian HEls were among the top 20 in the world and the fifth in Africa in terms of publishing in predatory journals. The experience of delay in peer reviewing and processing of manuscripts to publish in local and 
well-credited international journals and the motivation to get promoted for better pay seem to be factors that encourage faculty at HEls to look for alternatives journals which grant easy publishing. As a step forward to improve the situation and the quality of publications from local scholars so that their works will have scientific value internationally, the Ministry of Science and Higher Education (MOSHE 2019) has drafted staff promotion guidelines - one element of which is the requirement to publish in the Web of Science or the Scopus indexed journals.

This account reveals that academics in Oman and Ethiopia face similarly strong pressures to publish in international journals due to promotion regimes and indicators of academic quality being linked to global rankings. However, language hierarchies and publishing traditions were strikingly different in these two countries. A strong tradition of English-medium education and publishing in Ethiopia contrasted with Oman where Arabic-medium education and journal article publishing is well established and considered equal status to English language. A significant difference is the historical dominance of the English language in Ethiopian HEls, as compared to Oman - where differences in the medium of instruction can be seen between the sciences (English) and humanities (Arabic), strongly influencing publishing capability and preferences.

\section{Theoretical Framework}

The concept of 'academic literacies' underpins this research study, as a way of exploring how institutional practices and values influence how researchers make decisions about whether or where to publish, which languages to use and which texts to cite or build on in their writing. Jones, Street and Turner (1999) challenged the assumption of one homogeneous Academy and pointed to the importance of understanding writing (and reading) practices within 
specific academic contexts. Within an 'academic literacies' approach, questions of power and inequality are considered central to exploring questions of difference as Lea and Street (2010: 370) explain: 'particular attention [is given] to the relationships of power, authority, meaning making and identity that are implicit in the use of literacy practices within specific institutional settings'. We adopt this lens to analyse not only academic literacies within the case study universities but also how they position themselves and engage with global institutions, particularly in academic journal publishing.

Integral to this framework is the concept of literacy as a social practice (Street 1984). Rather than assuming one universal neutral literacy, this model recognises multiple literacies and draws attention to local literacies and languages in relation to the dominant 'schooled' literacy and language (often English). In the context of academic writing and publishing, this approach enables us to analyse 'whose meaning dominates and how meanings are contested and mediated' and explore questions of voice and writer identity which 'become more complex in writing that emerges from multilingual processes' (Robinson-Pant and Wolf, 2017: 11). Lillis and Curry's (2015: 131) concept of 'literacy brokers' in academic writing and publishing (with peer review being seen as 'one type of high stakes brokering activity') is particularly valuable for considering the ways in which texts are mediated between researchers, reviewers, editors and publishers based in different institutions.

Taking these ideas about academic literacy being shaped by differing values and practices in different institutional and cultural contexts, we set out to compare academics' decisions and views about writing and publishing in two contrasting institutions.

\section{Methodology}


The research took the form of a qualitative comparative case study conducted by researchers who come from the specific country context and are familiar with the institutions as well as the academic literacy practices and languages discussed. Mitchell's (1984) distinction between a 'typical' and 'telling' case study is useful to explain how these two 'telling' case studies were chosen and also to warn against generalising from these case study findings to other institutions. In choosing to compare universities in Oman and Ethiopia, we noted characteristics which suggested that there would be important differences in their approaches and engagement with academic publishing, as discussed earlier. We noted significant differences between the two universities with regard to their institutional policies and staffing. In particular, the Oman university employed a large percentage of academics from outside the country and in the Ethiopian university, women academics made up a very small minority so there were particular policies to address gender inequalities in publishing.

The research question addressed in both case studies was:

- How do specific university priorities influence knowledge production, particularly academics' decisions about academic writing and publishing?

Within the Ethiopian University (ETU), eight (5 male/3 female) faculty members were selected randomly from 6 colleges to participate in the study. In terms of rank, while three of them are Associate Professors, five of them are Assistant Professors, with experience ranging from 5 to 17 years with an average of 12.13 years. All the participants reported that they were involved both in teaching and research. In terms of specialisation, they are from different disciplines: geography, disaster management, social work, chemistry, law, psychology, English language teaching, and soil science. While two of the participants completed their studies abroad, the remaining six are local graduates. The number of publications they each have ranged from 4 
to 49 (which actually is an outlier) and the total number of articles published between them was 79.

In the Omani university (OMU), a sample of 10 faculty members was selected from the College of Education, using purposive sampling based on their availability and their suitability to answer the research questions. The sample varied by nationality (3 Omanis/7 non-Omanis), and by gender ( 8 male/2 female). Three of the participants held senior leadership positions in the college. The sample included two professors, two associate professors and six assistant professors. Six of the participants received their PhDs from Western universities, namely the US, the UK and Australia, and the remaining four from their respective Arab countries. All participants were active in academic writing and publishing as they published between 8 and 50 papers, with the total number of journal publications exceeding 200.

As mentioned above, while the Ethiopian sample included participants from different disciplines, the Omani case only involved participants from the College of Education. This was due to practical reasons around availability and access. Given the evidence from previous research studies around how academic literacy practices differ greatly across disciplines (Castello and Donahue 2012), we are aware of this limitation in our study with regard to the Omani sample.

Semi-structured interviews were used to collect data after following the ethical approval procedures in each university. The participants were asked about the language they use for writing manuscripts, motives for publishing, how they select journals to send manuscripts, whether they prefer local or international journals, how they decide order of authorship when they publish jointly with others, peer review experiences and challenges faced in publishing. 
The responses of the participants were analysed under four thematic categories - the 'how', 'where' and 'why' of publishing, and reasons for publishing in international journals.

In OMU, nine interviews were conducted in Arabic and one in English depending on the preferences of interviewees. The interviews were recorded using a digital voice recorder and later transcribed for the purpose of analysis. The data generated were organised and coded using the MaxQDA software programme. In ETU, due to COVID-19 restrictions, the interview was conducted via email (in English). The analysis was carried out using the inductive method and thematic coding was employed to identify emerging themes and categories.

\section{Introducing the two case studies}

In this section, we expand on the institutional context influencing academics' publishing decisions, drawing on (anonymised) documentary sources from each case study university.

The Ethiopian University (ETU) was established in 2000. Currently it is one of the largest universities in the country running more than 80 undergraduate, more than 100 masters and more than 50 PhD programs. ETU has over 2000 local and 50 international academic staff (with less than $20 \%$ female staff). The language of instruction is English as is the case at all universities in Ethiopia, meaning that most academics prepare manuscripts for publication in English. So far, staff engagement in teaching has been given more weight than the other two required areas of work, research and community services. University legislation declares that a teaching staff needs to devote $60 \%$ of the time for teaching, $25 \%$ for research and $15 \%$ for community service. Though it declares different teaching (25\%) and research (60\%) loads for research staff, at the moment there are no members formally employed as research staff.

Staff promotion at ETU mainly considers four criteria - effective teaching, publications, participation in university affairs, and engagement in community service. The minimum 
weights given to the criteria vary for promotion to different ranks. While teaching effectiveness and publication have an equal minimum required weight ( $35 \%$ each) for promotion from Lecturer to Assistant Professor, more than the minimum is given for publication (35\%) than effective teaching (30\%) for promotion to Associate and Full Professorship. Regarding participation in university affairs, the minimum required weight is the same for promotion to all ranks. Concerning community services, relatively more engagement is expected from applicants for a full professorship (10\%) than those for an assistant and associate professorship (5\%).

At ETU, points for publication vary according to the quality of the journal where the article is published. The common practice is to assign one point for one article publication. But, if an article is published in a web of science indexed journal, 1.25 will be counted. The university has a scheme of monetary reward for publications, with those publishing in web of science journals getting more money than those publishing in other journals.

ETU encourages joint research work and publications. The research and community services guideline of the university clearly stipulates that funds for research projects will be granted for a team of researchers and at least one female academic should be in any team. This is to encourage female academics to engage in publishing. Regarding publication points, a staff will earn 1 point for a sole authorship, 0.75 point each for two co-authors and 0.60 point each for three or more co-authors for an article.

$\mathrm{OMU}$ is a public institution established in response to a growing demand for higher education following the expansion of pre-tertiary education after Sultan Qaboos took power in 1970 (AlLamki, 2002). The university offers programmes in a variety of academic disciplines, ranging from science and technology to social sciences and humanities. The university has a diverse 
faculty, with non-Omani staff representing almost one-third of the total academic and teaching working force. They are employed on a contract basis, and renewal depends on annual performance appraisals conducted by their respective departments. Omani staff are appointed on a permanent basis. For both groups, promotion to higher academic ranks depends on performance in three areas: teaching, scholarship, and university and community service, with excellence in the area of scholarship having more weight than the two other areas.

Although OMU started as mainly a teaching-oriented institution, the focus has now shifted toward creating more balance between teaching and research. The Deanship of Research assumes responsibility for scientific research in the university with a vision to make it a top research institution in the Arabian region. In order to achieve this goal, the Deanship implements policies aimed at building capacity and increasing research engagement and output.

Encouraging academic writing and research publication is a significant component of the OMU's plan to build research capacity and to boost its international reputation by engaging in internationally-recognised research. Since it recognises the importance of research output as 'one of the main pillars of an institution's international ranking', the university encourages its members to publish their research in international journals, including through the launch of a publication reward scheme providing monetary rewards for publishing in journals indexed in the Web of Science or Scopus. The value of the reward is determined based on quartile rankings (Q1, Q2, Q3 or Q4) and the nature of the database (WoS/Scopus), with publications in Q1 journals indexed in the WoS receiving the highest scores. In addition to indexed international journals, the university has a list of recognised Arabic journals where 
publication is recommended. Yet, the rewards are not as high as those allocated for international journals. Though there is no requirement to publish in open-access outlets, some colleges even offer financial support to academic members who choose to do so.

\section{Exploring comparative perspectives on publishing experiences}

\section{Why publish?}

As indicated above, both universities used publication as an important criterion within promotion systems, though differences emerged in the analysis as to how far this influenced academics' motives for publishing and writing.

In OMU, institutional pressures played an important role in pushing the participants to write and publish and they related these to academic promotion and contract renewal. There were significant differences between the Omani and non-Omani staff, though promotion was mentioned by both. For example, Amira, a female Omani participant stated that the main motive for her to publish was her intention to apply for promotion. She recalled that when she wanted to apply, she was slowed down by her realisation that she had not published enough papers to make her application successful.

Contract renewal was specifically an issue for non-Omani participants. 'The nature of our work here is that we have contracts, so we must publish,' commented Samira, a senior nonOmani participant, supported by Ahmed, another non-Omani participant who explained that this was 'because of the performance appraisal.' Nabil pointed out that though he was selfmotivated, when he moved to OMU he felt pressured to write and publish as part of contract renewal requirements. An Omani participant, Amira, also raised this issue, stating that contract renewal places more pressure on non-Omani colleagues in her department. She added that many of them were outstanding in teaching, yet did not have their contracts 
renewed due to lack of publications. However, some participants perceived the pressure on non-Omani staff positively, reasoning that it pushes them to be academically active and productive. According to Adel, this explains why non-Omanis usually produce more research than their Omani peers.

While institutional pressures emerged as a significant factor, personal development through writing and publishing seemed to be equally important for most participants:

For me it's about personal growth. It's also part of my career as an educationist. (Samira) I also want to publish in order to amalgamate the different pieces of knowledge that I get to learn from others... Research in itself has its own value in a sense. What I mean is that through research we develop even in life...Research in itself is important. (Kamal)

There are also personal motives why you publish because it's your academic life...Your job is to do research, so you need to develop yourself through reading and researching. (Ahmed)

Some participants wanted to be recognised by the academic community in their fields and considered writing and publishing as a means to achieve this ambition. Adel confirmed that even if there was no pressure, he would still publish for his own reputation as a scholar, saying it made him feel valued to publish in high quality journals: 'a researcher's contribution to this field determines his value'. The same idea was underscored by other participants:

I want to publish to be promoted. I want to publish more importantly to be recognised in the field as a scholar in my area. (Kamal) 
For me, [writing] is the activity through which I express my academic identity...It's the means through which I communicate my ideas to others who are reading my research. (Nabil)

Similarly, the respondents in Ethiopia revealed that institutional as well as personal pressures motivated them to publish. In particular, this was a criterion for promotion, as a senior academic commented:

As a professor teaching at higher education it is one of my obligations to publish different research works. Currently the senate legislation of the university put publishing as one obligation of academic staffs within a certain interval. Apart from this, in order to promote a certain rank to another higher rank publication is one of the mandatory requirements. (Yonas)

Under the university legislation, it is stated that a staff member needed to spend $25 \%$ of time for research. Haimanot, a female academic from social sciences, stated that this implied an indirect pressure on the staff to publish:

... the University encourage us to spend $25 \%$ of our time to research and community service by reducing teaching load. Publication is one criterion for promotion so indirectly there is pressure to publish

For many participants, it was the personal motive to be promoted (which has implication for salary increases) to the next academic rank which overweighed any institutional pressure or encouragement for publishing: 
I have interest to publish and its part of my future career goals.... For me the pressure to get publish [ed] is more of internal (from myself). There is no as such demanding pressure from my university and respective leaders. (Almaz)

Comparing the two universities, we found that academics' main motive was for promotion but that they also saw publishing as an important aspect of professional development - and in ETU, this was part of their designated work as an academic. In OMU, important differences emerged between the Omani and non-Omani staff, with more institutional pressures evident on the latter in order to retain their contracts.

\section{Writing and publishing practices: experiences and challenges}

The interviews explored academics' experiences of writing and publishing, including decisions they made at a micro level about how to collaborate with colleagues and, in the case of OMU, which language to write in.

In ETU, seven of the eight participants had written publications collaboratively with other authors. An important aspect in relation to joint publication mentioned in the interviews was deciding on the order of authorship and one factor was principalship in winning a grant for research:

... the order of authorship was decided by the one who was PI and had brought the funding (Almaz)

We have decided the order of authorship based on .... who took the initiative to lead the research, who played a significant role in winning the research grant (Kibrom) 
Another factor for determining the order was the supervisee-supervisor relationship between the authors. Particularly when publications arose from the supervisee's project, the supervisee would be named the first author:

The ... article was extracted from my thesis, [hence] it was a default to put me first and my supervisors next based on their contributions (Almaz)

.... and if the author (s) is/are PhD/MSc/MA [student], by default he/she will be the first author (Kibrom)

On the other hand, in science disciplines the interviews revealed that authorship order was based on experimental engagement:

we gave priority to the person who did experiment to be first author (Haimanot)

Participants also talked about their experiences of writing for peer-reviewed journals, particularly the challenges of responding to reviewers' comments and their perceived 'subjectivity', as Genet commented: 'I believe that the reviewing process follows a scientific method and is critical, but it still has issue of subjectivity. Sometimes there could be biases.' Haimanot expressed irritation at responding to reviewers who wrote 'without presenting adequate/ scientific reasons', similar to Almaz who resented 'biased and misunderstood reviewers' comments and I hate replying to such reviewer'.

The delays in processing and the time demands were other aspects that frustrated the participants when writing for peer-reviewed journals:

It takes too much time, sometimes I think that it is a matter of luck for one to get through the process (Genet) 
Another participant signalled the difficulty of juggling writing with other tasks required in the university, such as teaching and community service:

The first most important thing is the devotion of time and focus which requires. If I detach from the writing for a while, I have to start all over again. (Almaz)

In the interviews in $\mathrm{OMU}$, the language in which they wrote their research was a strong factor influencing decisions. Since all participants were native Arabic speakers, they had publications in the Arabic language. However, with regard to writing in English, a different picture emerged. Seven out of the ten participants interviewed already had some English publications, while two other participants have not yet had their first English paper published. Ahmed, a non-Omani participant, stated that he has never tried to write in English as he did not have the required language skills. Different patterns emerged as to how those who wrote in both languages tried to balance their Arabic/English publications; some participants published more English than Arabic papers, whereas others published mostly in Arabic. For instance, Kamal mentioned that about $70 \%$ of his publications were in English: 'It's because of training, my study. I did my MA and my PhD in English language teaching. It's by preparation'. Samira stated that she writes mostly in Arabic as she finds it easier and faster to write in her first language.

As in the Ethiopia case study, participants showed a general preference for collaborative work, suggesting that this could be a learning opportunity as well as a means to enrich the research:

In individual work, you know your abilities and your own thoughts, but you don't know about other people's ideas, so through joint work you get the opportunity to see other ideas and other schools of thought, so you will definitely benefit. (Ahmed) 
When we work together, we can cover a topic from different angles...Individual work will not produce the depth that group work can produce. (Hussein)

However, some participants believed that the benefit of collaborative work was conditional upon finding the right collaborators, which was not always possible. Amir attributed this to what he perceived to be a lack of 'teamwork culture' among Arab researchers, coupled with the absence of a shared research agenda that would bring them together. According to him, this resulted in researchers leading their own research and working in isolation from other colleagues. Kamal added:

The problem with this is that although I like it, it's not easy at all to find the right person to work with. It's just the chemistry between two people ...I like people who are easy going in terms of schedule, who are open to different ideas, who don't basically burden you with most of the job and do just a little.

Some participants viewed collaborative writing as a useful strategy to overcome the difficulties associated with writing in English. Working with colleagues who could write in English was highlighted as a useful practice that should be encouraged and promoted. There was a case of a particular participant (Adel) who used this strategy successfully and was able to co-author a number of papers written in English, even though he had no prior experience of this.

Comparing perspectives from the two universities, OMU participants appeared to put a stronger emphasis on the learning opportunities offered by collaborative writing. However, they noted a tendency for researchers to work independently as it had not been their normal practice to work in a team. By contrast, in ETU, collaborative writing was taken as the norm and their discussion focused on how they made decisions about whose name went first on 
the publication. They also drew attention to the powerful role of reviewers and how far their comments could be taken as 'unbiased'. These were issues that emerged in the following section too and relate to the notion of 'literacy brokers' (Lillis and Curry, 2015) referred to earlier, as well as the challenges of mediating identity and voice across cultural boundaries (Robinson-Pant \& Wolf 2017).

\section{Where to publish?}

The data revealed that participants' decisions about whether to publish their research in local or international journals were determined by quite different factors in OMU and ETU.

Most important in OMU was the language in which they write and how this influenced their choice of journal. Not all participants were able to write in English, so the language barrier was highlighted as a significant challenge hindering some of them from publishing internationally. They blamed this on the nature of their initial and postgraduate training which was mainly in Arabic. Yassin commented: 'Writing in English requires you to master the language, let alone the language needed for academic writing...I haven't had a chance to be trained in this during my postgraduate studies'. When asked why he did not publish in English, Ahmed responded: 'Due to my preparation. The whole preparation programme was in Arabic...I haven't had the opportunity to study abroad...I haven't had the opportunity to get English language preparation'. Hussein supported this: 'You know that the writing language we are familiar with in Egypt is Arabic, which has caused a big problem. For three years I have been trying to shift from Arabic to English and it's a big struggle because the two languages are completely different'.

However, some participants believed that there was much more to writing for international journals than simply possessing English language proficiency, as Nabil noted: 'It's not only to 
do with the language barrier; I know many people who studied abroad but they didn't have the required skills...It's also a matter of motivation at the end of the day'. He explained that the whole process is so complicated that it pushed many Arab scholars (especially in the social sciences) to 'choose the easy path' (publish in Arabic) for reasons to do with the lenient review process, short review time and the availability of a large number of Arabic journals. Hussein agreed, noting: 'The main barrier is [English] language, but it's not everything. Writing the research report, the techniques of structuring the paper, selecting the topic...'. This relates to Canagarajah's (2002) notion of the 'discursive' constraints faced by scholars in the Global South.

Kamal pointed to the complicated nature of the review process as an impediment to publishing internationally:

I think it's tough; the reviewing process is tough. A lot of people go through the easy way. They think that publishing in a very robust journal with a very tough process of review takes ages, which is frustrating to them, so they tend to go for local or regional, maximum. This was confirmed by other participants who believed that though some Arabic journals may conduct lengthy and tough peer reviews, international journal reviews were tougher and time-consuming:

Publishing in Arabic is much easier... Reviews are very few... Most papers are accepted without revisions and published quickly. (Amira)

In Arabic journals it's much faster and less demanding. International journals sometimes do multiple rounds of reviews. (Nabil) 
Turning to ETU, language choice was not mentioned in relation to how participants selected the journals where they sent their manuscripts and they were more concerned about the reputability of the journal. As Yonas explained:

My first benchmark to decide where to publish is the reputability of the journal and its wider acceptance by the academic community (Yonas)

Reputability was understood by participants in different ways:

I have been looking ... its reputability; volume number; whether the journal is in the web of science/Scopus or not (Kibrom)

I usually select journals that are indexed and which publish articles on teaching and learning English from researchers from the developing world (Kassa)

Other than indexation of journals, there were personal judgments regarding the quality of journals selected too. An academic from a language department explained that he decides where to send manuscripts after reading articles published by the journal:

I determine the quality of a journal by the complexity of the language used in writing the articles and by the extent from which it is free of language errors. The other factors that determine the quality of a journal for me are how rigorous the methodologies are (Kassa)

But high quality journals were not always preferred as participants were concerned that the possibility of rejection may be high:

If I think the journal has a high quality, I may not send my article to it because its chance of being published will be very low (Kassa)

Colleagues' recommendations were also mentioned as the basis for selecting a journal: 
Sometimes colleagues who have published in a specific journal may suggest that I can also publish in that specific journal, and I may take their advice (Kassa)

[I select journals based on] suggestions by colleagues in the research team and my PhD teachers (Almaz)

Another factor that participants considered in selecting journals was its relevance:

[I select a journal] if I believe that a journal is interested on the issue I am addressing; based on the decision I make that the information I am addressing is suitable to local or international community (Ezra)

The interview data from ETU and OMU showed that academics in both institutions were taking pragmatic decisions about where to publish. Whereas in ETU this was based on relevance and rigour of the journal, as well as time/resources involved, in OMU the decision was strongly related to their confidence in writing in English. It was notable that in both universities, respondents took account of the intended readership only once they had made the decision to target that specific journal - rather than first considering which audience/purposes their research might be useful for or how they could engage in dialogue with a broader audience. As we explore below, the question of readership was closely connected with the status of the journal and the associated instrumental benefits (citations, promotion) of becoming known within a broader international academic community.

\section{Why international journals: a question of status or quality?}

In both ETU and OMU, a significant issue related to journal selection was whether academics targeted journals published locally or abroad. In ETU, there was a more general preference 
for journals published abroad rather than locally. This is reflected in the number of articles the participants collectively published - out of a total of 76 articles published, 64 were published in journals abroad. One reason was stated to be the better reputability, efficiency and rigour of journals abroad than local journals:

I prefer journals abroad instead of those published in Ethiopia due to the question of reputability, the time it takes, and transparency (Kibrom)

But in addition to reputability, the desire to reach a broader readership was considered important:

I prefer journals abroad due to their reputability and hoping publishing abroad would increase the accessibility of my work and brings more recognition to my future research projects. (Almaz)

I prefer journals abroad since they have more readers than local journals and improve my citation index. I feel that local journals are not respected in Ethiopia. (Ezra)

Speed of processing and ease of the system for submission and follow up as well as inadequate number of local journals were important reasons:

[I prefer journals] abroad because there is not a well-established [online platform] system to [easily] submit/follow progress/publish an article. I think experienced professional in Ethiopia are not encouraged to establish a system like what we have seen abroad. (Anteneh)

I always publish in journals overseas because there are few journals in Ethiopia, and some of the journals in Ethiopia may take longer to publish articles. (Kassa) 
However, not all of the participants were in favour of international journals. A professor from the Law Faculty explained the difficulty of publishing comments of cases (case comments) which are based on the local legal context and language:

I prefer journals published in Ethiopia. Because it is difficult to publish in international journals articles and case comments that are written in local language. In relation to legal research and case comments, I personally believe that publishing in local language is more accessible for the audience and wider community (Yonas)

A professor from the College of Science also noted that the context of study influenced whether he selected local or international journals:

It depends on the work. For example, if the work aims on quality of food in one region of Ethiopia, as it interests local readers, I prefer Ethiopian journal otherwise I prefer international journals (Haimanot)

In $\mathrm{OMU}$, most participants perceived writing for international publication as an important aspect of their career, albeit for different reasons. While some believed that it was instrumental in facilitating promotion and securing new contracts, others felt that it was crucial for their academic growth and recognition as scholars. For example, when asked why he chose to publish in international journals, Adel replied: 'Two things: first recognition as a scholar; second, it's a requirement of the institution for promotion and publication rewards'. He preferred to publish in journals indexed in Scopus or Web of Science because they were recognised by the university and also because they brought him good reputation through citation. Hussein commented: 'If you are not existent on search engines and you don't have citations or a Google Scholar account, you are completely out of the game'. For Kamal, it was 
about reaching a wider audience: 'It's just maybe I thought I would have a wider audience if I go for an international journal'.

From the institution's point of view, emphasis on international publication was justified by its perceived role in improving OMU's reputation worldwide, as Sami, a senior leadership member, explained: 'More visibility for the institution. The visibility of OMU mainly relies on publishing in the English language'. He seemed proud of the growing number of faculty members who publish internationally. Although he believed that publishing in Arabic was important, he pointed out that it would not contribute much to enhancing OMU's international recognition: 'We also encourage publishing in Arabic, but the problem is that till now there is not a system to calculate the impact factor or citation index for the Arabic journals. That's why we encourage international publishing'.

Nonetheless, the participants felt that there was too much pressure to publish in international journals and this was more evident among non-Omani faculty staff. Amir seemed particularly annoyed with what he perceived as 'excessive emphasis' on this issue:

I want to publish something of value. I always question the benefit of what I publish. They want us to publish in international journals, so I wonder what is the percentage of people who will benefit from this research and read in English... I mean if I don't see the value of what I'm doing, it will be problematic for me to do it...Yes publishing will arouse your pride and make you feel satisfied, but when you look at the value of what you publish, that's the issue... This makes me write under stress.

While acknowledging the importance of international publication, most participants believed that it was equally important to write in Arabic and publish in local journals. Sami emphasised this point: 'We encourage colleagues who write in Arabic to publish because we must provide 
Arab readers with high quality scholarly work in Arabic'. Amir agreed, reasoning that Arab researchers must keep in mind their audience and publish work that is relevant and of real value to Arab readers.

In both ETU and OMU, the respondents saw international journals as offering instrumental benefits in relation to promotion but also the possibility to share their work and gain respect as a scholar in a broader academic community. Significantly, they recognised the importance of publishing in regional journals too, where the work could be directly relevant and beneficial to local audiences. In ETU, the decision was also related to the greater perceived rigour, transparency and efficiency of the peer review process in international journals as compared to Ethiopian journals. OMU participants commented however that publishing in Arabic was quicker. A question that arose through the comparative analysis was how far the institutional imperative to publish in international journals might over-ride decisions to publish locally.

\section{Discussion}

Viewed through an 'academic literacies' conceptual framework, the above comparative analysis contributes insights into how academics' decisions about and experiences of writing and publishing were shaped by institutional values, both at a local level and by global hierarchies around knowledge construction - in particular, indicators such as the Web of Science had become embedded in institutional promotion regimes. How academics chose to position themselves in relation to local and international journals was partly in response to institutional promotion criteria. But significantly in both universities, they emphasised that decisions were also based on the perceived quality and rigour of international journals, as well as the importance of professional development. The different employment conditions for Omani and non-Omani academics in OMU had resulted in the latter having a more 
extensive publication record, particularly in English language international journals. A recent report on the top OMU authors for the period 2014-19 included nine names, seven of which were non-Omani.

Though the findings generally support earlier academic literacies research (see Curry and Lillis, 2010) on pressures to publish in English, important differences between the two contexts emerged too. Language issues played out differently in specific disciplines, especially between sciences and humanities in OMU, and for law researchers in ETU, who needed to publish cases in Amharic for local audiences. Whilst global language hierarchies - particularly English language being perceived as higher status - clearly influenced academics' publishing in both contexts, the findings also offered insights into how local institutional and disciplinary values, and issues around voice and identity, shaped publishing decisions. It was notable that concerns around who would read and engage with their research rarely took account of language issues - an exception being Amir's frustration that his colleagues would be less likely to read his articles if published in English rather than Arabic. Adopting an academic literacies lens pointed to the importance of analysing how writing and reading practices are embedded in relationships of power, particularly at a micro institutional level. In the case of OMU, where there was a high proportion of non-Omani staff like Amir, decisions about language and publishing needed to be analysed in relation to their differing contractual obligations, academic status and identities. Whilst insider/outsider issues emerged in the Omani data, gender hierarchies and inequalities appeared to be shaping academic literacy practices in the Ethiopian institutional case (where academics were encouraged to have a female member as co-author). 
Promotion emerged as a significant motive for academics at both ETU and OMU to write and publish, supporting Tien's (2000) finding that faculty members who exhibit higher motivation towards promotion produce more publications. Foreign OMU participants, however, appeared to be driven more by their concerns about contract renewal, as indicated above. While contract renewal can push academic staff to be more productive, it may also cause jobrelated stress (Mark and Smith, 2018), which, in the case of short-term contracts, could create a work environment that is not conducive to writing and publishing (Lim, 1999).

Adopting an academic literacies lens involves challenging the starting point that literacy is an individual activity and to explore the ways in which writing is embedded as a social practice. This led us to situate the analysis of academics' publishing experiences in relation to networks of peer reviewers, editors, readers beyond the university as well as within each institution. Interviews with academics in both institutions revealed that some academics valued collaboration with their local colleagues. In $\mathrm{OMU}$, some respondents suggested that collaboration brought the possibility of working with colleagues more fluent in English, though there was evidence too that an individualised culture worked against this practice. In ETU, collaborative writing - between supervisor and supervisee and within funded research project teams - appeared to be the norm and respondents explained the local conventions established around authorship recognition, some of which did not adopt established academic hierarchies (such as their policy to put a PhD student's name first). Collaboration was not only at the level of writing, but also sharing ideas with peers about experiences of different journals, including their peer review process and timeliness of publishing.

Although the higher status of international journals was mentioned in both universities as a reason for choice (particularly in relation to promotion regimes, and contract renewal in the 
case of OMU), issues around academic identity were also important considerations. Respondents welcomed the opportunity to gain a voice in a global academic community through international publishing. An important aspect from both sets of data was that international journals were not only considered to reach a larger audience, but were also seen to be more rigorous in their peer review and more efficient. In $\mathrm{OMU}$, though there was a commitment to publishing in Arabic as well as English, questions around journal quality were also key factors in academics' decision making.

We set out to problematise the concept of 'international' journals in the interviews (as we have in this paper). However, we found that respondents were more likely to challenge the dominance of, say, English language over Arabic language publications, than to contest the hierarchies established by and associated with 'international' journals. Our finding that all respondents saw the term 'international' (in relation to journals) as a fact rather than a social construction is perhaps the strongest indication of how the values and practices of journals published in the Global North can become deeply embedded in higher education institutions in diverse areas of the world.

\section{Conclusion}

Our data has revealed how academics in Oman and Ethiopia situated themselves in relation to the geopolitics of academic publishing. The analysis raises questions about how to address publishing inequalities - not only at an individual or university level but also regionally and internationally. Within this broader context, international journals could play an important role in developing ways to prevent 'publication drain' and strengthen national/regional journals. For instance, editors of 'centre' journals could establish a partnership with editors of journals with a similar focus in the Global South - particularly national journals. This could 
help international editors to understand more about readers and writers in the South, resulting in greater diversity of topics and contexts covered. As Hallinger and Hammad (2019: 300) note: 'During an era when "social justice" represents a defining value for the field, it seems strange that our journals are not making more active efforts to encourage broad representation of international scholarship from developing societies'. Through such partnerships, national and 'in-house' journals could benefit through developing more rigorous peer review processes. One way to challenge the geopolitics of academic publishing could be for journals based in the Global South to work for 'international' recognition through developing the quality indicators required by publishers in the UK and US. An example of a national and university-based journal which succeeded in becoming an 'international' journal is the Iranian Journal of Language Teaching Research (ijltr.urmia.ac.ir), based at the University of Urmia and now indexed in the Web of Science (ESCI) and SCOPUS. Although at one level this could be considered as strengthening the existing hierarchies in academic publishing established through such indices, such a step could help to challenge the common assumption that 'international' high status journals are based only in countries of the Global North.

There is a strong need for academic institutions like OMU and ETU to take a lead in exploring ways to address some of the hierarchies (journal ranking, languages) highlighted in our analysis. For instance, in the Arab region, the Association of Arab Universities has launched an initiative in collaboration with Elsevier to support Arabic journals in preparation for their inclusion in their database, thus making Arabic sources/knowledge more visible to the international audience. They have also launched a project aimed at creating an Arab impact factor. Whilst such developments can be promoted for a dominant/widely spoken language like Arabic, it is more difficult to see how Amharic and other national languages could be recognised and promoted within academic publishing in this way. 
The need to build a research agenda relevant to the region has never seemed more pressing in the cases of both Ethiopia and Oman, though as our analysis has revealed, this is often in conflict with universities' priorities for improving their global reputation. Although respondents noted that publishing in Arabic could be faster and more accessible, their university valued the status of 'international' publication - even though this would be a much slower route with less chance of engaging with an audience who understood and could interact with the researchers. As Hallinger and Hammad (2019; 31) argue: 'In the current global higher education environment, universities will continue to press individual scholars towards doing whatever is necessary to publish, without regard to a broader or more meaningful agenda'.

\section{References}

Abouchedid, K., \& Abdelnour, G. (2015). Faculty research productivity in six Arab countries. International Review of Education, 61(5), 673-690.

Adamson, J. \& T. Muller (2017). Reviewer feedback on multilingual scholars' writing for English publication: perspectives from the 'periphery.' Writing and Pedagogy, 8(3), $519-536$

Al-Lamki, S. M. (2002). Higher education in the Sultanate of Oman: The challenge of access, equity and privatization. Journal of Higher Education Policy and Management, 24(1), 75-86.

Almansour, S. (2016). The crisis of research and global recognition in Arab universities. Near and Middle Eastern Journal of Research in Education, 2016(1), 1-13.

Arnsbjornsdottir, B. \& Ingvarsdottir, H. (2017) Issues of Identity and Voice: Writing English for Research Purposes in the Semi Periphery, in Curry and Lillis (2017) 
Bridges, D. (2017) The International and the Excellent in Educational Research and its Assessment, Philosophy and Educational Research: Epistemology, ethics, politics and quality, Springer

Canagarajah, S. (2002). A Geopolitics of Academic Writing, Pittsburgh: University of Pittsburgh Press

Castello, M. and C. Donahue (2012) University Writing: Selves and Texts in Academic Societies, Bingley: Emerald Group Publishing

Cook, C. (2017). Predatory journals: The worst thing in publishing, ever (Editorial). Journal of Orthopedic \& Sports Physical Therapy, 47(1), 1-2

Curry, M.J. \& T. Lillis (2017) Problematising English as the privileged language of global academic publishing, in Curry \& Lillis (eds) Global Academic Publishing: Policies, Perspectives and Pedagogies, Bristol: Multilingual Matters

Dados, N. and R. Connell (2012) The Global South, Contexts 11 (1), 12 - 13

Demir, S. B. (2018). Predatory journals: Who publishes in them and why? Journal of Informetrics, 12, 1296-1311

Derebssa Duffera. (2004). The status of research undertaking in Ethiopian higher education institutions. The Ethiopian Journal of Higher Education, 1(1), 83-104.

El-Zeki, A. (2008). Arab education issues in some international educational journals: An analytical study. Resalat Al Khaleej Al-Arabi, 29 (107), 13-58.

EAS (Ethiopian Academy of Sciences) (2017). National journal evaluation and accreditation: A strategy for standardizing the assessment of performance in scholarly publishing in Ethiopia. Addis Ababa: Author 
Fejes, A. (2016). The politics of publishing in research journals within the field of adult education and learning, Symposium at the ESREA triennial conference in Maynooth, September 2016 [unpublished notes]

Findlow, S. (2006). Higher education and linguistic dualism in the Arab Gulf. British Journal of Sociology of Education, 27(1), 19-36.

Hallinger, P., \& Hammad, W. (2019). Knowledge production on educational leadership and management in Arab societies: A systematic review of research. Educational Management Administration \& Leadership, 47(1), 20-36.

Hanafi, S., \& Arvanitis, R. (2014). The marginalization of the Arab language in social science: Structural constraints and dependency by choice. Current Sociology, 62(5), 723-742.

Hanafi, S., \& Arvanitis, R. (2015). Knowledge production in the Arab World: The impossible promise. Routledge

Hanafi, S. (2011). University systems in the Arab East: Publish globally and perish locally vs publish locally and perish globally. Current Sociology, 59(3), 291-309.

Ibrahim, B. (2018). Arab Spring's effect on scientific productivity and research performance in Arab countries. Scientometrics, 117(3), 1555-1586.

Jones, C., Street, B.V. \& Turner, J. (1999) Student writing in higher education: Theory and practice, Amsterdam: John Benjamins

Kuteeva, M. \& A. Mauranen (2013) Writing for publication in multilingual contexts: an introduction to the special issue, Journal of English for Academic Purposes, 13, 1-4

Lea, M. \& B.V. Street (2010) The 'academic literacies' model: theory and applications', Theory into Practice, 45(4), 368-377 
Lillis, T. \& Curry, M.J. (2015) The politics of English, language and uptake: the case of international academic journal article reviews, AILA Review 28 (2015), 127-150, DOI: 10.1075/aila.28.06lil

Lillis,T., Magyar, A. \& A. Robinson-Pant (2010) An international journal's attempts to address inequalities in academic publishing: developing a writing for publication programme, Compare, $40(6), 781-800$

Lim, D. (1999). Quality assurance in higher education in developing countries. Assessment \& Evaluation in Higher Education, 24(4), 379-390.

Lulseged, S., \& Howe, R. (2020). Evaluation of scholarly publications: Practice and prospects for Ethiopia (Editorial). Ethiopian Medical Journal, 58(1), 1-2

Mark, G., \& Smith, A. P. (2018). A Qualitative Study of Stress in University Staff. Advances in Social Sciences Research Journal, 5(2) 238-247.

Ministry of Science and Higher Education (MOSHE). (2019). Directive for establishing and implementing a national system of journal evaluation and accreditation (Directive no. 02/2019). Addis Ababa

Mohamedbhai, G. (2013). Towards an African Higher Education and Research Space (AHEARS): A summary report. Association for the Development of Education in Africa. Available at http://www.adeanet.org/en/system/files/resources/ahers summary report.pdf

Robinson-Pant, A. \& A. Wolf (2017). Researching across languages and cultures: a guide to doing research interculturally, London: Routledge 
Salager-Meyer, F. (2015) Peripheral scholarly journals: from locality to globality. Iberica, 30, $15-36$

Street, B.V. (1984). Literacy in Theory and Practice, Cambridge: Cambridge University Press Tesfaye, S. (2011). Educational research and the Ethiopian Journal of Education (EJE) in the past decade (2000-2009): Contributions, downsides, and the way forward. Ethiopian Journal of Education, 31(2), 107-143

Tien, F. F. (2000). To what degree does the desire for promotion motivate faculty to perform research? Testing the expectancy theory. Research in Higher Education, 41(6), 723752.

Windle, J. (2020). Recontextualising race, politics and inequality in transnational knowledge circulation: Biographical resignifications. Research in Comparative and International Education, 1745499920946202. 